\title{
Online Teaching of College Physics with Multi Teaching Methods and Temperature
}

\author{
Yanhua $\mathrm{Li}^{*}$, Xinshun Wang \\ Department of Optoelectronic Science, Harbin Institute of Technology at Weihai, Weihai, China \\ Email address: \\ lyhyzh2020@163.com (Yanhua Li),xinshunwang66@163.com (Xinshun Wang) \\ ${ }^{*}$ Corresponding author
}

\section{To cite this article:}

Yanhua Li, Xinshun Wang. Online Teaching of College Physics with Multi Teaching Methods and Temperature. Science Journal of Education. Vol. 9, No. 2, 2021, pp. 27-31. doi: 10.11648/j.sjedu.20210902.11

Received: February 24, 2021; Accepted: April 1, 2021; Published: April 12, 2021

\begin{abstract}
As a public basic course for undergraduates in science and engineering colleges, college physics course focuses on imparting basic knowledge and scientific research methods, with the significant characteristics of rich teaching content and wide coverage. Exploring an effective teaching mode of college physics has always been the goal of college physics teachers. In the course of COVID-19's destruction, it is urgent to explore the online teaching mode of college physics. This paper explores the integration of college physics teaching methods during the epidemic period, and tries to build a teaching mode that relies on the platform to support the integration of multiple teaching methods. Relying on the MOOC platform of China University, first of all, we provide students with an online learning network space through the asynchronous SPOC of the platform; Secondly, We effectively combine Tencent conference interactive teaching, QQ real-time interaction and MOOC classroom follow-up test as the online classroom teaching scheme; Finally, the multi-dimensional teaching evaluation mode is used to test the learning effect. We share the possible accidents in the online classroom and the author's online teaching experience, trying to make students feel a warm and an effective online college physics classroom during the epidemic specific period.
\end{abstract}

Keywords: College Physics, Online Classroom, Multidimensional Evaluation

\section{Introduction}

In early 2020, the "New Coronavirus" epidemic swept the whole country and the whole world. In the face of the epidemic, Wu Yan, director general of the Higher Education Department of the Ministry of education, pointed out: colleges and universities can provide 24000 online courses, and it is completely feasible to promote online teaching at the university level [1]. Based on this, the school has put forward the decision of delaying the opening of offline courses and carrying out online teaching, and has released various teaching technology platforms and software to realize online teaching, so as to ensure that students from all over the country will "stop classes without stopping school".

Online teaching for public basic education, is a challenge for teachers, especially for the long-term use of blackboard teaching mode of college physics course [2-10], how to carry out the course, how to carry out the classroom, teachers need to design in advance and release the relevant information to students; for students, the change of classroom form, will also let the students who are used to tracking the teacher blackboard learning not adapt, moreover, online teaching is not the same as webcast, Teachers need to consider all kinds of unexpected factors, innovate teaching mode, integrate multiple means, and consider the diversity of assessment methods to ensure that online and offline teaching is at least of the same quality and effect.

\section{Method}

\subsection{Combination Optimization of Online Teaching Platform}

\subsubsection{Platform Selection Principle}

The first choice of online teaching platform should be stable and sustainable background data support; secondly, it is convenient for teachers and students to operate; thirdly, it should consider the problem of students' learning tax reduction, and try to realize multi-functional operation on the same platform for the same course. The MOOC platform of China University has strong functionality, that is, learning by click. It has mobile App and can also be operated on 
computer web pages, and can track the traces of learning (learning duration, homework submission before and after class, etc.). The asynchronous SPOC operation based on the platform is flexible, which is convenient to select the online videos that fit with the textbook of this course, and can be supplemented and deleted according to the needs, and each chapter is equipped with appropriate information The exercises and test questions that can be added or deleted can enable students to check their learning effect through self-test, and can also be consulted and reviewed after class; the MOOC classroom based the platform can assess students' learning situation and carry out background data statistics in online classroom at any time; Tencent conference live broadcast has real-time voice communication function, after students ask questions, teachers can answer questions in real time, and teachers can communicate with each other through the shared screen function, it can be switched to the blackboard writing interface in real time. The blackboard writing and PPT images on the same screen provide a more intuitive sense of picture, which is suitable for interactive live broadcasting. QQ group, as a platform for real-time communication, in addition, QQ phone function serves as a backup scheme for live broadcasting of platform congestion, as well as a real-time answering question and homework delivery space outside the online classroom.

\subsubsection{Online Teaching Scheme}

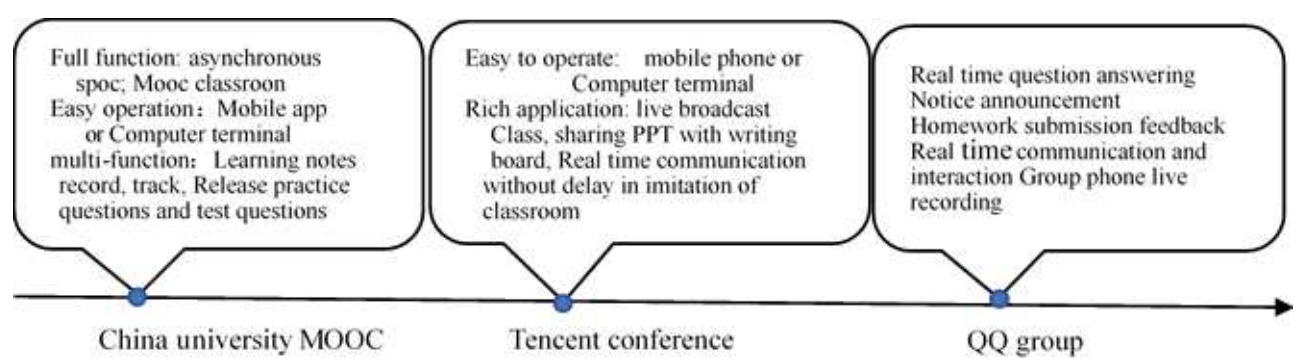

Figure 1. Online teaching scheme.

\subsection{Online Teaching Preparation: You Use Heart, Students Use Action}

\subsubsection{Teachers' Lesson-preparation}

Due to the relative stability of the basic framework and core content of college physics teaching content, to create a network space for students' autonomous learning, the most important is the teaching means, method and feasibility design [11-15]. The asynchronous SPOC based on China university MOOC platform is flexible in operation, it is undoubtedly a timely help for the situation that teachers have not built the course of college physics on the platform, but have accumulated a large number of teaching materials. During the epidemic prevention period, we firstly select the teaching video materials that match our school's teaching materials, and delete and supplement them according to the teaching content, so as to provide visual teaching materials for students the complete and refined materials, the preparation of supporting electronic teaching plan, including the brief text expression videos and pictures close to life and easy to understand animation presentation can be used as teaching resources for extended learning after class (link videos or articles that can be embedded in PPT); sorting, deletion and addition of MOOC test exercises in Chinese universities; making preparation, editing and entry, time node release setting of MOOC test questions corresponding to each chapter; high shot matching with traditional blackboard writing the function debugging of the projector blackboard; the account registration and function debugging of Tencent conference live broadcast; the establishment of QQ group and the release of teaching calendar in advance.

\subsubsection{Trial Broadcast and Debugging}

One week before the beginning of the course, the teacher issued an announcement through QQ group to let the students download the relevant teaching software in advance, and contacted the students to arrange the trial broadcast of the college physics course. The content of the trial broadcast is as follows:

(1) Introduce the online teaching mode, so that students can understand the online learning mode and arrange the learning progress with a definite aim.

(2) Introduce the asynchronous SPOC of Chinese University MOOC system and the related operation of MOOC classroom, and explains the use of platform tools and the functions we use.

(3) Release the requirements of online course. The grade consists of two parts, usual score and final exam result, usual score includes MOOC classroom test (each chapter is carried out in class at the end of each chapter and back-end data statistics), QQ group homework (each chapter of the textbook homework after class), self-test exercises and test questions of each chapter of asynchronous SPOC based on China university MOOC platform (check your learning effect through self-test and review before the exam after class)

(4) Experience the effect of Tencent conference live broadcast, learn to use the operation interface, and introduce the use of standby scheme.

It should be emphasized that the determination of live teaching software needs to interact with students to debug the online teaching effect of relevant software (such as Tencent classroom, Tencent conference, nail live, classroom dispatch, 
etc.), and finally choose Tencent conference (interactive real-time, no delay) online teaching mode after several times of debugging and voting. At the same time, remind the students to pay attention to the matters before class, such as: test the network speed in advance, adjust the volume of microphone and abide by the classroom discipline of online classroom.

\subsection{Live Teaching}

\subsubsection{The Teacher's Voice in the Studio Is Not Only the Eyes, But Also the Body Language and Comfort}

In addition to video communication with students before class, in order to ensure smooth communication, the camera was not turned on during the teaching process. Through the conference voice, combined with the feedback of the discussion area in the live room, QQ group and the activity data in the classroom, we can timely understand the students' learning situation. For example, in the "sign in" activity, although the process has been explained in the QQ group before class, some students still forget how to operate in confusion. At this time, the teacher's emotion will deeply affect the students' learning enthusiasm and effect. It is necessary to appease them with language. Let the voice tell them that you are not alone. Don't worry. Just take your time and get familiar with them to ensure that the students can feel the teacher's love and attention. At the same time, we should also consider the cultivation of university learning autonomy, not every class to carry out classroom check-in and classroom test, strict requirements for students, but also to fully trust students, through the class, after class statistics show that students can more consciously into the online classroom, to ensure the effective attendance and learning quality of the classroom.

\subsubsection{Slow Down the Speaking Speed, Students Are Better Than You Think}

The use of pre-prepared courseware for teaching is to make the explanation process clearer, but "blackboard writing" can be easier for students to understand for the traditional formula derivation. In the process of online teaching and explanation, the teacher plays PPT simultaneous interpreting and explaining the process with the high frequency projection and PPT screen, as well as the traditional blackboard teaching mode, and timely setting questions and discussions, students improved the participation of students in online teaching through bullet screen comments or independent discussion sessions. Especially when explaining PPT, try to slow down the speaking speed, give the students time, wait a little more, we will not miss the wonderful answer, the students are better than we think, at the same time, make an objective evaluation of the students' answers.

\subsubsection{The Accident of Online Teaching Strengthens the Spiritual Communication Between Teachers and Students}

Online teaching, there will inevitably be unexpected situation, once it happens, although it is a challenge for teachers, but also an opportunity, timely communication between teachers and students, students will be grateful. A student's SPOC answer was overdue and could not be submitted, he was very anxious emotionally. In view of this situation, he finally found out the reason by communicating with the MOOC instructor of China University and Mr. Zhang of the academic affairs office. The student entered the class of homologous SPOC.

\subsection{Online Teaching Evaluation}

The online teaching evaluation system of college physics consists of two parts: the usual score accounts for $20 \%$ of the total score, and the final closed examination score accounts for $80 \%$. The average score reflects the whole process of online teaching implementation, which is the whole process evaluation of the whole semester. It mainly includes two parts: one is the platform data support of MOOC, asynchronous SPOC and MOOC classroom test before, during and after class; The second is the feedback of each chapter under the QQ group operation function, including QQ homework and discussion on problems in QQ group. In addition, we also consider the students' activity in answering questions and interactive discussion in class in usual score accounts. As can be seen from Figure 2, the record of evaluation results runs through the whole teaching process, rather than just looking at the homework after class

\section{Experience of Online Teaching}

(1) Different from the traditional teaching, in order to deal with the unexpected situation, live teaching must have a backup plan, QQ phone backup live at any time. Due to the small number of online teaching classes in this class hours, Tencent conference live and MOOC classroom test have withstood the test in one semester.

(2) Compared with the traditional teaching, with the elaborate construction of students' online learning space, teachers need to pay more efforts and energy in the early stage of class, do a good job of real-time monitoring in the teaching process, push the background data of asynchronous SPOC and MOOC classroom test and QQ group assignments to students in real time, remind and urge the students who did not participate in the test and did not hand in the homework, which need teachers' investment after class more energy to complete, so that students can effectively manage the teaching environment in the real sense of autonomous learning. Especially in the asynchronous SPOC and MOOC classroom test, it is not only to check the students' mastery, but also to find out the shortcomings of teachers' teaching by testing and answering questions, so as to promote the improvement of teaching content and methods in further teaching. The interactive monitoring process is an important embodiment of the mutual benefit of teaching.

(3) The effective online teaching mode promotes the real interaction between teachers and students. Online teaching is different from face-to-face physical classroom, but warm 
language, slow speaking speed timely and patient comfort in unexpected situations can also strengthen the emotional communication between teachers and students. Characteristic teaching methods can shorten the distance with students, such as the star of homework evaluation - the best push of each chapter's homework; error correction expert - students can point out teachers' mistakes in writing and speaking in time when they watch electronic textbooks and online teaching, and so on. These measures will make students have a sense of satisfaction and pride in online learning, strengthen the spiritual communication between students and teachers and students in online teaching, and students can feel that college physics is an online classroom with temperature from the effective online teaching.

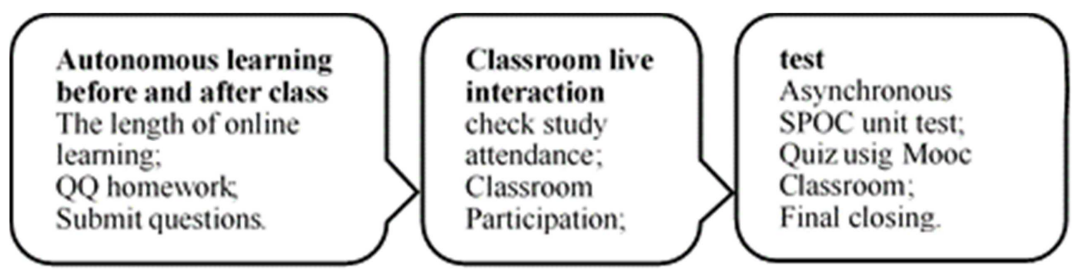

Figure 2. Performance appraisal scheme.

\section{Conclusion}

Online teaching has both advantages and disadvantages. For college physics teaching with a large number of students in the classroom, how to "avoid taking advantage" during the epidemic period is very important. The main design role of teachers is of vital importance. The design concept often determines the participation of students. Tencent conference live broadcast, asynchronous SPOC self-learning space design, accurate push of MOOC classroom, question answering of QQ space and the use of homework function, we create a multi-means fusion of college physics teaching mode with temperature. after class, the students' voice of thanks reflects the students' learning satisfaction during the epidemic period. At the same time, the exploration of online teaching of college physics taking the epidemic situation as an opportunity shows that: in today's rapid development of information technology, modern teaching methods have great educational potential in the construction of college physics curriculum, but to build college physics online curriculum, more teachers need to participate and form a teaching team.

\section{Acknowledgements}

The authors gratefully acknowledge the financial for this work by the support Project of Research Project of Teaching Reform in Shandong Universities (No. B2016M020) and Teaching Research Project of Harbin Institute of Technology at Weihai (No. ITGA 10002016)

\section{References}

[1] Ministry of education, Launched 22 online course platforms and 24000 courses [N]. People's daily, 2020-2-12.

[2] Jie Gao, Yiming Du, Xiuyue Guo, “An investigation of college students adaptability to online learningAn empirical analysis of online courses in Shaanxi Preschool Normal University,", Journal of Shaanxi Preschool Normal University, 2019, 3509, pp. 115-120.

[3] Xiaoping $\mathrm{Hu}$, zuoyu xie, "Analysis on the advantages and challenges of online teaching in universities under the epidemic situation," China higher education research, 2020, vol. 4. pp. $18-22$.

[4] Bo Zhao, Clara Zetkin, Zhihua Zhang, "The presentation and adjustment of college students'emotional state in the epidemic of new pneumonia -- from the perspective of self-care," China Youth Studies, 2020, vol. 4, pp. 49-54.

[5] Hongxin Wang, Jin Xu, Liping Yang, Saidi Wan. Study on the Learning Adaptability and Mental Health of Wuhan College Students During the Outbreak of COVID-19," Science Journal of Education. 2020, Vol. 8, No. 2, pp. 62-65. doi: 10.11648/j.sjedu.20200802.15.

[6] Wenhao Li, zhiting Zhu. "Improving emotional experience: J /Ol for relieving emotional problems of online learning during a pandemic, "China's audio-visual education: 1-62020-05-08.

[7] Zhuyuan Wang, Rui Zhang, Mu Gu et al, "Mixed teaching design and practice of college physics course based on SPOC," Physics and Engingeering, 2018, vol. 28 (4), pp. 3-19.

[8] Weimin Zheng, Xiaojuan Zhang, "Teachingpractice of college physics course under the background ofCOVID - 19 pandemic," 2020, vol. 39 (11), pp. 67-71.

[9] Shuhua Lu, Fang Tian, Lihui Wang, "Discussion and practice of College Physics Teaching Informatization," College Physics, 2019, vol. 38 (1), pp. 47-48.

[10] Xingxing Han, Youzhang Zhu, Haibo Niu, Exploration and practice of improving the teaching quality of online college physics in applied universities during the anti-epidemic period [J]. College Physics, 2020, 39 (11): 63-66.

[11] Cunyou Huang, Wenqing Shi, Zhengye Xiong, Yongqiang Li, "The Practice and Analysis of University Physics Teaching Based on Project Drive," Education Teaching Forum. 2019, vol. 17, pp. 161-162.

[12] Deting Hou, Qingfeng Liu, Hua Yang, Jinsong Miao, Dong-ling Song, "Exploration and Practice of Improving online College Physics Teaching Effect during Theanta-Covid-19 Period," Physics and Engineering. 2020, vol. 30 (3), pp. 11-15.

[13] Hailan, liu, Mu Gu, Tiangang Wu, Zhongqiang Ni, Zhihuai Song, "Reform and Practice of online blending teaching of "university physics "course," Physics and Engineering. 2020, vol. 30 (4), pp. 3-11. 
[14] Yunhuo Cui, Wensen Yu, Yuanxiang Guo et. al, "Exploration and Reflection on online teaching," Education Science, 2020, vol. 36 (3), pp. 1-24.
[15] Mingfei Cheng, Ling Zhou, Ju Peng, Jianhua Yang, "Creating online teaching of College Physics with temperature," College Physics, 2020, vol. 39 (12), pp. 61-63. 